\title{
A atividade cemiterial nos municípios brasileiros: Impactos ambientais, ordenamento jurídico e perspectivas futuras
}

\author{
The cemetery activity in Brazilian municipalities: Environmental impacts, legal \\ ordinance and future perspectives
}

\author{
Camila Angélica Baum ${ }^{\mathrm{a}}$ \\ Valter Antônio Becegato ${ }^{b}$
}

${ }^{a}$ Doutoranda em Recursos Hídricos e Saneamento Ambiental, Universidade Federal do Rio Grande do Sul, Porto Alegre, RS, Brasil. End. Eletrônico: eng.camilabaum@gmail.com

${ }^{b}$ Professor Associado da Universidade do Estado de Santa Catarina, Lages, SC, Brasil. End. Eletrônico: valter.becegato@udesc.br

doi:10.18472/SustDeb.v9n3.2018.18185

Recebido em 17.01.2018

Aceito em 24.07.2018

ARTIGO - VARIA

\begin{abstract}
RESUMO
Esse manuscrito tem como objetivo apresentar os impactos ambientais decorrentes da atividade cemiterial tradicional e as questões jurídicas que a envolvem, além de apontar tendências futuras para a destinação dos corpos. Para o desenvolvimento deste trabalho, utilizou-se uma abordagem qualitativa e exploratória utilizando bibliografia nacional e internacional, sítios eletrônicos e legislações associadas ao assunto abordado. Os resultados dessa pesquisa indicam os cemitérios como um problema para o planejamento urbano sem resolução definitiva a curto prazo. A legislação brasileira, apesar de recente e de impor regras para o estabelecimento desses empreendimentos, ainda apresenta muitas lacunas. Os cemitérios verticais e crematórios têm ganhado espaço nas discussões e se tornaram alternativas consolidadas para a destinação dos corpos, no entanto, o formato tradicional de cemitérios ainda é preferência. Apesar de todos os impasses ambientais e urbanísticos, a destinação de corpos em cemitérios horizontais continuará sendo a principal forma de destinação dos corpos na próxima década.
\end{abstract}

Palavras-chave: Contaminação; Políticas Públicas; Cemitérios; Resolução Conama no 335/2003.

\begin{abstract}
This manuscript aims to present the environmental impacts resulting from the traditional cemetery activity and the legal issues involved. Besides, it points out future trends for the destination of the bodies. For the development of this work a qualitative and exploratory approach was used, studying national and international bibliography, electronic sites and legislations linked to the subject addressed. The results of this research indicate that cemeteries are a problem for the urban planning, without a definitive resolution in the short run. The Brazilian legislation, although recent and imposing rules for the constitution of these ventures, still presents many gaps. Vertical cemeteries and crematories have gained space in the discussions and have become consolidated alternatives for the destination of
\end{abstract}


bodies. However, the traditional format of cemeteries is still preference. Despite all the environmental and urbanistic impasses, the destination of bodies in horizontal cemeteries will prevail during the next decade.

Keywords: Contamination; Public Politics; Cemeteries; Conama Resolution no 335/2003.

\section{INTRODUÇÃO}

A existência dos cemitérios é muito antiga tendo como objetivo as inumações de corpos. Durante os séculos XVIII e XIX, houve as mudanças mais significativas na história cemiterial e de sepultamento de corpos, em decorrência da preocupação com a salubridade pública, gerada pelas grandes epidemias ocorridas (AQUINO; CRUZ, 2010).

Atualmente, vivemos um novo momento de transformação na forma de inumações dos corpos e nas formas de destinação destes, desencadeado pelo aumento populacional, expansão urbana e contaminação ambiental, esta última ocasionada por subprodutos da decomposição dos corpos. $\mathrm{O}$ aumento populacional elevou consideravelmente as demandas por espaço nos centros urbanos, provocando a justaposição de zonas residenciais e cemiteriais (HARIYONO, 2015; NECKEL et al., 2017) e tornando a verticalidade uma solução alternativa para atender às necessidades de espaço na área urbana (HARIYONO, 2015).

Não menos importante, as comprovações científicas de contaminação do solo e das águas superficiais e subterrâneas na área de influência de alguns cemitérios, por seus aspectos construtivos e locacionais serem inadequados (PACHECO, 2000), têm impulsionado uma nova transformação na forma de destinar os corpos.

A relevância social dessas estruturas também tem sido alvo de questionamentos, haja visto o decréscimo das taxas de visitação, mudanças nas práticas de enterramento, como cremações, e questionamentos acerca do espaço ocupado por cemitérios estar vinculado a uma obrigação de "cuidado perpétuo", e que, no entanto, frequentemente caem em desuso e se tornam abandonados (DAVIES; BENNETT, 2016; WOODTHORPE, 2011).

Em decorrência de repetidas constatações de contaminação pela atividade cemiterial, em 2003 foi criada a Resolução Conama no 335, que dispõe sobre o licenciamento ambiental de cemitérios e questões envolvendo aspectos construtivos e regulamentação cemiterial. Mais tarde, nos anos de 2006 e 2008, a Resolução em questão sofreu alterações, por meio das Resoluções Conama no 368/2006 e no 402/2008. Atualmente a responsabilidade pela adequação e licenciamento ambiental dos cemitérios é de competência dos órgãos estaduais e municipais (BRASIL, 2008).

Ao apresentar os aspectos religiosos e sanitaristas, que conduziram a atividade cemiterial ao modo como é realizada atualmente, busca-se entender como ocorreram as mudanças nessa atividade ao longo dos séculos, e vislumbrar possíveis caminhos que permitam as adequações ambientais necessárias para que a atividade de destinação dos corpos não cause danos ao meio ambiente e que ao mesmo tempo continue sendo um rito religioso. Nesse sentido, esse manuscrito tem como objetivo apresentar os impactos ambientais decorrentes da atividade cemiterial tradicional e as questões jurídicas que a envolvem, bem como apontar tendências futuras para a destinação dos corpos.

\section{METODOLOGIA}

Para desenvolvimento deste trabalho, utilizou-se uma abordagem qualitativa e exploratória. Nessa perspectiva, para o desenvolvimento teórico da pesquisa, fez-se uso de bibliografia nacional e internacional, sítios eletrônicos de entidades públicas oficiais e legislações nacionais e estaduais associadas ao assunto abordado. 
Com relação ao ordenamento jurídico, utilizou-se a Resolução Conama no 335/2003 e o planejamento urbano, a partir dos quais foram explorados os aspectos relacionados aos impactos ambientais decorrentes da atividade cemiterial tradicional, questões jurídicas e tendências futuras para a destinação dos corpos.

\section{RESULTADOS E DISCUSSÃO}

\subsection{HISTÓRICO SOBRE SEPULTAMENTOS E CEMITÉRIOS}

Grande parte dos relatos históricos acerca dos sepultamentos remete ao período da Era Comum, também conhecida como Era Cristã, na qual ao longo dos anos a prática do sepultamento sofreu diversas alterações, relacionadas principalmente ao uso e ocupação do espaço urbano e à sanidade ambiental.

Na Europa, até meados do século XIV, a ideia que predominava a respeito da morte era de que esta era uma viagem espiritual da alma, sendo comum o sepultamento dos corpos nas catacumbas e no interior e proximidades das igrejas. Com a propagação da Peste Negra pela Europa, em 1348, que culminou na morte de aproximadamente um terço da população europeia até 1351 , iniciou-se uma alteração na forma como as pessoas viam a morte, sendo que, a partir dessa época, o apodrecimento do corpo após a morte tornou-se algo mais significativo (TUCHMAN, 1989, apud MACHADO, 2006).

Contudo, foi somente no século XVIII, após as epidemias de tifo e tuberculose, que políticas públicas relacionadas à sanidade ambiental e higiênica dos sepultamentos começaram a ser desenvolvidas, sendo vedada a prática dos sepultamentos nas igrejas (AQUINO; CRUZ, 2010).

Aos poucos, no final do século XVIII, surgiram os cemitérios, os caixões individuais e as sepulturas para famílias, época em que a medicina urbana analisava lugares de acúmulo de "tudo que pudesse provocar doenças". Nesse período, a partir da teoria dos miasmas, os médicos recomendavam o isolamento dos mortos para que os vivos estivessem protegidos da influência destes (CAMPOS, 2007). No início do século XIX, o avanço dos estudos da medicina urbana e as constantes crises de mortalidade impulsionaram o desenvolvimento de normas mais modernas e condizentes com a saúde humana, que acabaram resultando em uma política pública voltada ao estabelecimento de cemitérios públicos (MACHADO, 2006).

No Brasil a história foi muito semelhante à ocorrida na Europa. Inicialmente não havia nenhum controle higiênico e de sanidade ambiental, e a população, juntamente com as instituições religiosas, apresentava grande resistência ao controle estatal dos cemitérios. Apesar disso, em 1890, com a publicação do Decreto no 789 , consolidou-se a denominada secularização cemiterial, e o poder público obteve o domínio administrativo dos cemitérios (RIBEIRO, 2008).

Apesar de todo o avanço e alterações ocorridas na história cemiterial, devido à forma com que foram estabelecidos até o final do século XX, a maioria dos cemitérios existentes no Brasil encontra-se na condição de fonte poluidora, causando danos ao meio ambiente e possivelmente à saúde humana.

\subsection{PLANEJAMENTO URBANO E OS CEMITÉRIOS}

Os cemitérios representam um pouco de um enigma, quando se trata de planejamento urbano, por serem considerados uma peça essencial de infraestrutura social, um acessório sagrado e por serem permanentes na paisagem (DAVIES; BENNETT, 2016). Contudo, Hariyono (2015) destaca que o mercado imobiliário e as necessidades das populações urbanas estão aumentando e não há possibilidade de substituir o espaço destinado a estas por cemitérios.

A instalação de cemitérios é uma atividade que requer de seus responsáveis diversos cuidados em relação à alocação no espaço urbano e no meio ambiente. No Brasil, atualmente, compete aos municípios a organização de seus serviços públicos, incluindo os cemiteriais, incumbência esta que 
está expressa na Constituição Federal de 1988, no Art. 30, inciso V, o qual estabelece que: "Compete aos municípios organizar e prestar, diretamente ou sob regime de concessão ou permissão, os serviços públicos de interesse local [...]". O inciso VIII desse mesmo artigo ainda deixa claro que é competência dos municípios "promover, no que couber, adequado ordenamento territorial, mediante planejamento e controle do uso, do parcelamento e da ocupação do solo". A competência para organizar serviços públicos de interesse local é um reflexo do Princípio Constitucional da Autonomia Administrativa Municipal.

No que tange aos cemitérios privados, o Poder Municipal pode limitar sua ocorrência por meio de normas administrativas no âmbito da competência de interesse local e das Leis Municipais que especificam tais diretrizes ou condições, além da implantação estar condicionada à autorização deste ente, por meio do ato de permissão (MACHADO, 2006). Nas Leis Orgânicas, Planos Diretores ou Legislações, os municípios possuem disposições sobre planejamento urbano, ordenamento territorial e uso e parcelamento do solo, que indicam possíveis áreas para implantação de cemitérios, seja de ordem pública ou privada.

A Lei Federal $n^{\circ} 10.257 / 2001$ estabelece os instrumentos para aplicação da política urbana, entre os quais está o planejamento municipal, em especial o Plano Diretor, que disciplina o parcelamento do uso e ocupação do solo, e o zoneamento ambiental. O Plano Diretor é o instrumento básico da política de desenvolvimento e expansão urbana, e o mesmo deve apresentar as exigências fundamentais de ordenação da cidade, sendo obrigatório para as cidades com mais de 20.000 habitantes. Para estes, casos como o parcelamento do solo urbano devem estar previstos no plano municipal ou em lei municipal, os quais não podem estar em desacordo com o Plano Diretor, visto que este é instrumento básico da política de desenvolvimento e expansão urbana (BRASIL, 2001).

De acordo com as leis municipais brasileiras de parcelamento, do uso e da ocupação do solo e de zoneamento ambiental, os cemitérios são enquadrados em diversas zonas diferentes, de acordo com o estabelecido por cada município. Davies e Bennett (2016) afirmam que os cemitérios não se encaixam perfeitamente nas definições simplistas de zoneamento do uso do solo por não serem industriais, comerciais ou residenciais, e nem um espaço aberto. Apesar disso, as leis que definem o parcelamento, o uso e a ocupação do solo determinam que para a instalação de novos cemitérios seja realizado o Estudo de Impacto de Vizinhança, devido ao potencial que eles possuem em causar alterações significativas no ambiente.

Não obstante, a implantação de cemitérios é dependente das condições ambientais do local, visto que esse tipo de empreendimento possui potencial contaminante (NECKEL et al., 2017; SILVA et al., 2008). A análise desse aspecto permite que os planejadores repensem novas soluções e informem à população sobre os riscos existentes de viver perto de cemitérios (NECKEL et al., 2017).

De acordo com Davies e Bennett (2016), as propostas para cemitérios e crematórios em áreas residenciais ou próximas a elas são geralmente fortemente contestadas pelos residentes locais. Nesse contexto, uma solução para reduzir a contaminação gerada por cemitérios poderia ser a realização de um zoneamento juntamente com a análise de impacto social e ambiental envolvido, o que permitiria o tratamento de efluentes e gases, não expondo o solo à contaminação por necrochorume (DAVIES; BENNETT, 2016).

\subsection{REFLEXOS AMBIENTAIS DA ATIVIDADE CEMITERIAL}

Cemitérios representam uma fonte de responsabilidade ambiental devido ao seu potencial para acumular e liberar grandes quantidades de contaminantes gerados pela decomposição de cadáveres (NECKEL et al., 2017). Um corpo humano em decomposição, com peso entre $70 \mathrm{~kg}$ e $80 \mathrm{~kg}$, libera cerca de 30 litros de necrochorume (AQUINO; CRUZ, 2010), que é um líquido potencialmente poluidor e que altera as características físico-químicas e biológicas do solo (MAJGIER; RAHMONOV, 2012). Segundo Jonker e Olivier (2012), a maior parte da contaminação decorrente das atividades cemiteriais é originada a partir de cargas minerais que são liberadas e de subprodutos, como monóxido de carbono (CO), dióxido de carbono (CO2), metano ( $\mathrm{CH} 4)$, amônio ( $\mathrm{NH} 4)$ e nitrato (NO3), além de aminas biogênicas, 
como a cadaverina e a putrescina (FIEDLER et al., 2012).

Além do necrochorume oriundo da decomposição dos corpos, há também o necrochorume proveniente da decomposição dos caixões e de seus adereços, dos tecidos utilizados para vestir o corpo morto e da cama do caixão. Os tecidos utilizados para fins funerários são produzidos com materiais de difícil degradação, além de também receberem tratamento com ligantes químicos (WILLIAMS et al., 2009). Já a madeira utilizada para os caixões é normalmente tratada com conservantes, tais como cloreto de polivinilo, creosoto ou inseticidas (JONKER; OLIVIER, 2012; MININNI et al., 2007), bem como vernizes e seladores (JONKER; OLIVIER, 2012) que, ao se degradarem, liberam substâncias tóxicas nocivas (SPONGBERG; BECKS, 2000).

Diante da multiplicidade de substâncias que compõem o necrochorume e da potencialidade contaminante destas, é de grande importância a análise de aspectos geológicos e hidrogeológicos na escolha de locais para a instalação de cemitérios (SILVA; MALAGUTTI FILHO, 2008), uma vez que o solo funciona como filtro na retenção dos metais, dos microrganismos e das demais substâncias resultantes do processo de decomposição dos corpos (ÜÇISIK; RUSHBROOK, 1998).

Solos argilosos, com grande área superficial específica e alta capacidade de troca de cátions (CTC), são os mais adequados, por maximizar a retenção de metais pesados e líquidos humorosos (ÜÇISIK; RUSHBROOK, 1998), os quais podem conter em sua composição organismos patogênicos que, caso percolem até atingir o lençol freático, podem se tornar agentes de contaminação ambiental e causar problemas de saúde pública (ŻYCHOWSKI, 2012). Como esses ambientes têm poluentes potenciais e são fontes pontuais de poluição, populações que vivem perto de cemitérios podem estar expostas a níveis elevados de contaminantes altamente prejudiciais à saúde humana (OLIVEIRA et al., 2012).

Diante de tal contexto, em 1951 foi desenvolvido o primeiro estudo que se tem registro referente ao impacto dos cemitérios em águas subterrâneas, por Van Haaren, na Europa, e desde então diversos estudos referentes ao assunto foram desenvolvidos, a fim de se obter maior conhecimento sobre esse passivo ambiental. Em 1998, a fim de reunir e divulgar em um único documento o estado de conhecimento sobre a contaminação da água a partir do necrochorume e os mecanismos operacionais para amenizar o potencial de poluição, a World Health Organization (WHO) divulgou um relatório acerca dos impactos dos cemitérios no meio ambiente e na saúde pública. Nesse relatório também foram fornecidas algumas sugestões sobre a localização de áreas futuras para a prática cemiterial (UÇISIK; RUSHBROOK, 1998).

No Brasil, o primeiro estudo referente à preocupação da atividade cemiterial com o meio ambiente que se tem conhecimento é de Bergamo, apresentado em 1954 no IV Congresso Interamericano de Engenharia Sanitária, no qual ele defendeu a necessidade de estudos geológicos e sanitários das áreas de cemitérios e a verificação da possibilidade de poluição e contaminação das águas subterrâneas e superficiais. Contudo, apenas em 1991, em um estudo coordenado pelo professor Alberto Pacheco, após monitoramento realizado na área interna de três cemitérios, foi constatada a contaminação bacteriológica do aquífero freático por microrganismos oriundos de corpos em decomposição. Desde então foram desenvolvidos diversos estudos referentes à avaliação do impacto ambiental e na saúde pública decorrentes da atividade cemiterial, abrangendo a contaminação microbiológica e de metais pesados nas águas subterrâneas, estudos geofísicos, entre outros (PACHECO, 2000).

Em 2001, Bolívar Antunes Matos, orientado pelo professor Alberto Pacheco, realizou um importante estudo, no qual foi verificada a contaminação das águas subterrâneas pela atividade cemiterial de forma mais intensa nas sepulturas com menos de um ano, localizadas nas cotas mais baixas, próximas ao nível freático (MATOS, 2001). Além disso, este autor ainda observa a ausência de normas federais sobre o assunto e recomenda no final de seu trabalho a elaboração destas, indicando a inserção dos cemitérios na lista de fontes potenciais de contaminação das águas subterrâneas. 


\subsection{LICENCIAMENTO AMBIENTAL DE CEMITÉRIOS}

Em decorrência da ausência de obrigatoriedade de licenciamento ambiental de cemitérios no Brasil, visto que nas Resoluções Conama nos 001/1986 e 237/1997, onde são indicadas as atividades ou empreendimentos sujeitos ao licenciamento ambiental, os cemitérios não foram considerados e, impulsionado pelos estudos de Matos (2001) e Pacheco (2000), que apontam a atividade cemiterial como potencialmente poluidora, o Conama regulamentou o licenciamento ambiental de cemitérios horizontais e verticais, através da Resolução n 335/2003.

Atualmente, o ordenamento jurídico que trata da construção e regulamentação cemiterial é contemplado pelas Resoluções Conama nos 335/2003, 368/2006 e 402/2008. Considerando a necessidade de revisão da Resolução no 335/2003, em 2006 ela foi alterada parcialmente pela Resolução no 368, sofrendo algumas modificações em função das particularidades existentes em áreas de proteção de mananciais localizadas em regiões metropolitanas (BRASIL, 2006). Mais tarde, em 2008, houve uma nova alteração parcial da Resolução no 335/2003, por meio da Resolução no 402/2008, a qual concedeu aos órgãos estaduais e municipais de meio ambiente prazo até dezembro de 2010 para "estabelecer critérios para a adequação dos cemitérios existentes em abril de 2003" (BRASIL, 2008).

Para os cemitérios horizontais, a Resolução no 335/2003 e suas alterações estabelecem exigências mínimas que devem ser atendidas, relacionadas à altura da sepultura, caracterização do subsolo, distanciamento da sepultura até a altura do nível máximo do aquífero freático, técnicas e práticas para o sepultamento de corpos, localização da área de sepultamento, técnicas e práticas que permitam a troca gasosa e critérios para cemitérios horizontais em áreas de mananciais para abastecimento humano (BRASIL, 2003). Também é apresentado um prazo de regularização para os cemitérios preexistentes a abril de 2003 que estivessem em desacordo com a Resolução e um Plano de Encerramento das atividades (BRASIL, 2003).

Outra exigência da Resolução Conama no 335/2003, que afeta também outros empreendimentos do ramo funerário, é de que "os corpos sepultados poderão estar envoltos por mantas ou urnas constituídas de materiais biodegradáveis, não sendo recomendado o emprego de plásticos, tintas, vernizes, metais pesados ou qualquer material nocivo ao meio ambiente", recomendação esta que altera o mercado de urnas funerárias e que dá alusão à possibilidade de contaminação química decorrente da decomposição dessas urnas.

O descumprimento das disposições das Resoluções supracitadas sujeita o infrator às penalidades previstas na Lei no 9.605/1998, que trata dos Crimes Ambientais, e em outros dispositivos normativos pertinentes, sem prejuízo do dever de recuperar os danos ambientais causados, na forma do art. 14, $\S 1$ 1o, da Lei no 6.938/1981. A Lei de Crimes Ambientais, em consonância com a Constituição Federal de 1988, estabelece a obrigatoriedade do licenciamento ambiental das atividades degradadoras da qualidade ambiental e estabelece, ainda, que as atividades e condutas consideradas lesivas ao meio ambiente sujeitarão os infratores, pessoas físicas ou jurídicas, a sanções civil, penal e administrativa, independentemente da obrigação de reparar os danos causados (BRASIL, 1998).

Apesar da Resolução Conama no 335/2003 ter sido um marco no ordenamento jurídico nacional ante o potencial poluidor da atividade cemiterial, ainda é uma legislação com muitas lacunas. Nos Estados Unidos, conforme o ordenamento jurídico, os cemitérios devem apresentar propostas orçamentárias anuais com base em fundos de investimento destinados à gestão de cemitérios, junto com a manutenção e melhoria do cemitério (BROWN, 2013; DAVIES; BENNETT, 2016). Sousa et al. (2015), após avaliarem o perigo de contaminação a que estão expostas as águas subterrâneas subjacentes aos cemitérios, sugerem que a legislação brasileira avance no sentido de dirimir dúvidas sobre o funcionamento dos cemitérios, a sua carga contaminante e sua interação com as condições ambientais no meio onde se inserem.

No entanto, alguns estados brasileiros, antes mesmo do estabelecimento da referida Resolução, já haviam apresentado preocupação em relação a essa atividade, inclusive regulamentando-a no âmbito estadual. O estado de São Paulo foi um dos precursores no estabelecimento de ordenamento jurídico regulamentador da atividade de empreendimentos cemiteriais, sendo que o primeiro registro que se 
tem conhecimento é o Ato $\mathrm{n}^{\circ}$ 326, de 21 de março de 1932, do Município de São Paulo (MATOS, 2001), que disciplinava a construção de novos cemitérios, somente naquele município (SÃO PAULO, 1932).

Há de se considerar também que atualmente diversas legislações em âmbito estadual que tratam do assunto apresentam-se muito específicas e detalhistas, como é o caso da Instrução Normativa no 52, da Fundação do Meio Ambiente do Estado de Santa Catarina (Fatma), publicada em 2012, a qual define a documentação necessária para o licenciamento e estabelece critérios no âmbito ambiental para implantação de cemitérios.

A referida Normativa se apresenta em diversos pontos mais restritiva que a legislação nacional, com instruções específicas aplicáveis ao estado, no que tange aos aspectos geológicos, como por exemplo: (i) é vedada a instalação de cemitérios em terrenos constituídos predominantemente por rochas de decomposição carbonática (que comportam aquífero cárstico), cuja dissolução química provoca a formação de condutos subterrâneos nessas rochas, tipificados por cavernas, dolinas, sumidouros, rios subterrâneos e outros, e também naquelas áreas onde a superfície piezométrica mostra-se elevada à alagadiça; (ii) é vedada a instalação de cemitérios em terrenos localizados sobre aquíferos porosos/costeiros; (iii) é vedada a instalação de cemitérios sobre áreas de recarga de águas do Sistema Aquífero Guarani (SAG), cuja geologia é formada predominantemente por arenitos correlacionáveis à Formação Botucatu. Na ausência de alternativas locacionais, deverá ser analisada a viabilidade de instalação de cemitério vertical; (iv) em terrenos situados sobre o Aquífero Basáltico Fraturado Serra Geral, os cemitérios devem ser preferencialmente do tipo vertical; (v) para cemitérios localizados sobre o Aquífero Basáltico Fraturado Serra Geral deve ser apresentado estudo da geologia estrutural, acompanhado de mapa de lineamentos tectônicos (FATMA, 2012).

O fato de os estados apresentarem um ordenamento jurídico mais detalhista que o nacional garante que os aspectos regionais sejam levados em consideração para a concepção de empreendimentos cemiteriais, uma vez que a legislação nacional ainda apresenta algumas lacunas relativas aos diferentes aspectos regionais geológicos e hidrogeológicos, por exemplo.

\subsection{PERSPECTIVAS FUTURAS}

As perspectivas futuras no ramo cemiterial são abrangentes e, como tal, seguem o estabelecido pelo ordenamento jurídico brasileiro até o presente momento. No entanto, envolvem questões dogmáticas como no processo de cremação e, por outro lado, corpos sepultados em cemitérios horizontais, que podem levar à contaminação dos solos e de águas superficiais e subterrâneas, requerem cuidado e controle perpétuo.

Hariyono (2015), ao abordar sobre o espaço ocupado pelos cemitérios atualmente e no futuro, relacionando o espaço ocupado pelos túmulos, taxa de mortalidade e tamanho da população, apresentando o tamanho necessário para sepultamentos em grandes centros, observa a necessidade de se repensar a terra como local de sepultamento.

Cabe salientar que dentro das perspectivas futuras relativas à atividade cemiterial está a adequação dos cemitérios existentes em abril de 2003, quando foi publicada a Resolução Conama no 335/2003, que, de acordo com a Resolução Conama no 402/2008, delegou para os órgãos estaduais e municipais de meio ambiente o estabelecimento de critérios de adequação até dezembro de 2010. Mesmo que haja essa adequação para os cemitérios situados em locais com características geológicas e hidrogeológicas susceptíveis à contaminação, a adoção de ações que impeçam a contaminação pelo necrochorume de sepulturas preexistentes é de elevado custo e de difícil tramitação, uma vez que necessitaria de transformações nos espaços religiosos destinados à prática de sepultamento.

Nesse contexto, parte das discussões pertinentes ao assunto é sobre o desenvolvimento de novos empreendimentos cemiteriais tradicionais adequados à legislação, a aceitação e desenvolvimento de cemitérios verticais e a prática de cremação dos corpos. Há uma tendência no desenvolvimento de cemitérios tradicionais e cemitérios-parque ambientalmente adequados e de caráter privado, visto o desenvolvimento ocorrido no ordenamento jurídico relacionado e devido ao alto custo envolvendo a 
manutenção do espaço, custos do tratamento dos efluentes gerados e necessidade de solo adequado para essa finalidade (PACHECO, 2000).

Nas últimas décadas, outra alternativa que tem despertado interesse são os cemitérios verticais, por ocuparem áreas menores, cujos impactos ambientais são consideravelmente inferiores aos ocasionados por cemitérios tradicionais, quando a atividade é manejada de forma adequada, devido à ausência de interferência do necrochorume e resíduos nas águas subterrâneas, baixa exigência quanto ao tipo de solo e facilidade de sepultamento e visitas em dias chuvosos (CAMPOS, 2007).

De acordo com Hariyono (2015), estamos agora enfrentando a era da recriação de forma em verticalidade: campus universitários, museus, bibliotecas, edifícios de moda, instalações desportivas, juntamente com a combinação de todos estes misturados com tipologias residenciais, hoteleiras e de escritório. $\mathrm{O}$ mesmo autor ainda afirma que se apreciamos a sustentabilidade no manejo do solo, então a verticalidade é provavelmente a primeira opção a ser adotada.

Em um nível de interesse muito semelhante ao observado pelos cemitérios verticais estão os crematórios, principalmente pelo espaço ocupado por esses empreendimentos ser reduzido, custos mais baixos, popularidade de enterros "informais" em locais diferentes dos cemitérios tradicionais e devido a gerar impactos ambientais facilmente passíveis de controle (DAVIES; BENNETT, 2016). De acordo com Hariyono (2015), há um movimento de afastamento dos enterros tradicionais em direção às cremações como a escolha dominante de enterro. A cremação também se apresenta como uma prática adequada à modernidade, uma vez que os cemitérios tradicionais são espaços que simbolizam e evocam a memória de um grupo (THOMPSOM, 2015).

Apesar da tendência mundial de mudanças relacionadas à destinação de corpos, recentemente foi aprovada a Lei dos Cemitérios e Crematórios (2013) em um estado do sul da Austrália, onde a renovação de cemitérios é elencada como uma opção significando que muitos cemitérios de propriedade pública que atingiram ou estão se aproximando da capacidade estão no caminho para um possível abandono. Em contrapartida, a referida legislação exigirá, pela primeira vez, o registro de locais de enterro, informação esta que fornecerá uma base para o planejamento estratégico para áreas de sepultamento (DAVIES; BENNETT, 2016).

\section{CONSIDERAÇÕES FINAIS}

O planejamento urbano é atualmente um desafio em centros urbanos e os cemitérios horizontais são, assim como aterros sanitários, um empreendimento negativo, sob diversos pontos de vista. No entanto, a preferencial forma de destinação dos corpos é a tradicional, em cemitérios horizontais, demonstrando a contradição provocada por esses empreendimentos.

Apesar da evolução no ordenamento jurídico, no que tange à regularização de cemitérios, ele abre lacunas em relação à regularização dos cemitérios tradicionais preexistentes. Durante a realização deste trabalho, não foi encontrado, S.M.J., nenhum estudo que tratasse de práticas efetivas para regularização dos cemitérios que iniciaram suas atividades anteriormente a abril de 2003 e que se encontram em condição de passivo ambiental. Apesar do estabelecimento de ordenamento jurídico que considera aspectos construtivos, locacionais e de regulamentação ser um fato muito positivo, muitos cemitérios se encontram em condições inadequadas e, mesmo assim, não tiveram suas atividades interditadas, conforme estabelece a Lei no 9.605/1998.

No que tange às perspectivas futuras para inumações de corpos e nas formas de destinação destes, os cemitérios verticais e crematórios têm despertado interesse em nível mundial nos últimos anos, tanto por parte da gestão pública quanto por parte da sociedade. À gestão pública interessa pelo fato desses empreendimentos ocuparem espaço reduzidamente pequeno quando comparado aos cemitériosparque ou cemitérios tradicionais, otimizando o uso do solo.

As alterações nos costumes aos poucos têm modificado o pensar das pessoas em relação ao assunto abordado neste trabalho, no entanto, salienta-se que o sucesso dessas novas práticas para a destinação 
dos corpos necessita, sobretudo, de incentivo e políticas públicas que tornem essas práticas mais acessíveis, inclusive para a população de baixa renda.

\section{AGRADECIMENTO}

O presente estudo foi desenvolvido com auxílio da Fundação de Amparo à Pesquisa e Inovação do Estado de Santa Catarina - Fapesc na forma de bolsa de pesquisa, Chamada Pública processo no 05/2015.

\section{REFERÊNCIAS}

AQUINO, J. D.; CRUZ, M. J. M. Os riscos ambientais do cemitério do Campo Santo, Salvador, Bahia, Brasil. Cadernos de Geociências, v. 7, n. 1, p. 19-30, 2010.

BRASIL. Constituição da República Federativa do Brasil, de 5 de outubro de 1988. 11. ed. São Paulo: Atlasm, 1998.

BRASIL. Lei no 6.938, de 31 de agosto de 1981. Dispõe sobre a Política Nacional do Meio Ambiente, seus fins e mecanismos de formulação e aplicação, e dá outras providências. In: Diário Oficial da União, de 02 de setembro de 1981.

BRASIL. Lei no 9.605, de 12 de fevereiro de 1998. Dispõe sobre as sanções penais e administrativas derivadas de condutas e atividades lesivas ao meio ambiente, e dá outras providências. In: Diário Oficial da União, de 12 de fevereiro de 1998.

BRASIL. Lei no 10.257, de 10 de julho de 2001. Regulamenta os arts. 182 e 183 da Constituição Federal, estabelece diretrizes gerais da política urbana e dá outras providências. In: Diário Oficial da União, de 10 de julho de 2001.

BRASIL. Ministério do Meio Ambiente. Conselho Nacional de Meio Ambiente - Conama. Resolução no 001, de 23 de janeiro de 1986. In: Diário Oficial da União, de 17 de fevereiro de 1986.

BRASIL. Ministério do Meio Ambiente. Conselho Nacional de Meio Ambiente - Conama. Resolução no 237, de 19 de dezembro de 1997. In: Diário Oficial da União, de 22 de dezembro de 1997.

BRASIL. Ministério do Meio Ambiente. Conselho Nacional de Meio Ambiente - Conama. Resolução no 335, de 3 de abril de 2003. Dispõe sobre o licenciamento ambiental de cemitérios. In: Diário Oficial da União, no 101, de 28 de maio de 2003.

BRASIL. Ministério do Meio Ambiente. Conselho Nacional de Meio Ambiente - Conama. Resolução no 368, de 28 de março de 2006. Altera dispositivos da Resolução no 335, de 3 de abril de 2003, que dispõe sobre o licenciamento ambiental de cemitérios. In: Diário Oficial da União, no 61, 29 de março de 2006.

BRASIL. Ministério do Meio Ambiente. Conselho Nacional de Meio Ambiente - Conama. Resolução no 402, de 17 de novembro de 2008. Altera os artigos 11 e 12 da Resolução no 335, de 3 de abril de 2003. In: Diário Oficial da União, no 224, de 18 de novembro de 2008.

BROWN, T. The making of urban "healtheries": the transformation of cemeteries and burial grounds in late - Victorian East London. Journal of Historical Geography, v. 42, n. 100, p. 12-23, 2013.

CAMPOS, A. P. S. Avaliação do potencial de poluição no solo e nas águas subterrâneas decorrente da atividade cemiterial. 2007. 141 f. Dissertação (Mestrado em Saúde Pública) - Universidade de São Paulo, São Paulo, 2007. 
DAVIES, P. J.; BENNETT, G. Planning, provision and perpetuity of deathscapes - Past and future trends and the impact for city planners. Land Use Policy, v. 55, p. 98-107, 2016.

FIEDLER, S. et al. Graveyards - Special landfills. Science of the Total Environment, v. 419, p. 90-97, 2012.

HARIYONO, W. P. Vertical Cemetery. Procedia Engineering, v. 118, p. 201-214, 2015.

JONKER, C.; OLIVIER, J. Mineral contamination from cemetery soils: case study of Zandfontein cemetery, South Africa. International Journal of Environmental Research and Public Health, v. 9, n. 2, p. 511-520, 2012.

MACHADO, S. S. Análise ambiental dos cemitérios: um desafio atual para a administração pública. Revista de Ciências Humanas, v. 6, n. 1, p. 127-144, 2006.

MAJGIER, L.; RAHMONOV, O. Selected chemical properties of Necrosols from the abandoned cemeteries Słabowo and Szymonka (Great Mazurian Lakes District). Bulletin of Geography. Physical Geography Series, v. 5, n. 1, p. 43-55, 2012.

MATOS, B. A. A avaliação da ocorrência e do transporte de microorganismos no aquífero freático do Cemitério de Vila Nova Cachoeirinha, Zona Norte do Município de São Paulo. 2001. 172 f. Tese (Doutorado em Recursos Minerais e Hidrogeologia) - Universidade de São Paulo, São Paulo, 2001.

MININNI, G. et al. Dioxin, furans and polycyclic aromatic hydrocarbons emissions from a hospital and cemetery waste incinerator. Atmospheric Environment, v. 41, n. 38, p. 8527-8536, 2007.

NECKEL, A. et al. Environmental damage and public health threat caused by cemeteries: a proposal of ideal cemeteries for the growing urban sprawl. Revista Brasileira de Gestão Urbana, v. 9, n. 2, p. 216230, 2017.

OLIVEIRA, B. et al. Burial grounds' impact on groundwater and public health: an overview. Water and Environment Journal, v. 27, n. 1, p. 99-106, 2012.

PACHECO, A. Cemitério e meio ambiente. 105 f. Instituto de Geociências, Universidade de São Paulo, São Paulo, 2000.

RIBEIRO, A. L. R. Urbanização, poder e práticas relativas à morte no sul da Bahia, 1880-1950. $168 \mathrm{f}$. Tese (Doutorado em História) - Universidade Federal da Bahia, Salvador, 2008.

SANTA CATARINA. Fundação do Meio Ambiente. Instrução Normativa no 52. Versão Março 2012. Disponível em: <http://www.fatma.sc.gov.br/site_antigo/downloads/images/stories/Instrucao\%20 Normativa/IN\%2052/in_52.pdf>. Acesso em: 24 abr. 2017.

SÃO PAULO (Município). Ato $\mathrm{n}^{\circ} \mathbf{3 2 6}$, de 21 de março de 1932. Substitui o Ato $\mathrm{n}^{\circ} 1.321$, de 08 de abril de 1919, que dá regulamento aos cemitérios do Município. São Paulo: 21 mar. 1932.

SILVA, F.; SUGUIO, K.; PACHECO, A. Avaliação ambiental preliminar do Cemitério de Itaquera, segundo a Resolução Conama 335/2003, Município de São Paulo. Revista Geociências - UnG, v. 7, n. 1, p. 31-47, 2008.

SILVA, R. W. da C.; MALAGUTTI FILHO, W. Cemitérios como áreas potencialmente contaminadas. Revista Brasileira de Ciências Ambientais, Cubatão, v. 9, p. 26-35, 2008.

SOUSA, M. C. D. B.; MONTEIRO, C. A. B.; CASTRO, M. A. D. O uso da avaliação do perigo de contaminação do aquífero como um requisito para o licenciamento ambiental de cemitérios. Brazilian Geographical Journal: geosciences and humanities research medium, v. 6, n. 2, p. 137-153, 2015.

SPONGBERG, A. L.; BECKS, P. M. Inorganic soil contamination from cemeteries leeched. Water, Air, Soil Poll, v. 117, p. 313-327, 2000. 
THOMPSON, B. Cemitérios verticais, espaço urbano e meio ambiente: o novo discurso científico universitário de incentivo à verticalização do cemitério e cremação. Primeiros Estudos, v. 7, p. 07-26, 2015.

ÜÇISIK, A. S.; RUSHBROOK, P. The impact of cemeteries on the environment and public health, an introductory briefing. Copenhagen: WHO Regional Office for Europe, 1998.

VAN HAAREN, F. W. J. Cemeteries as sources of groundwater contamination. (em neerlandês). Water, v. 35, n. 16, p. 167-172, 1951.

WILLIAMS, A. et al. Environmental considerations for common burial site selection after pandemic events. In: RITZ, K.; DAWSON, L.; MILLER, D. (Org.). Criminal and Environmental Soil Forensics. Holanda: Springer, p. 87-101, 2009.

WOODTHORPE, K. Sustaining the contemporary cemetery: implementing policy alongside conflicting perspectives and purpose. Mortality, v. 16, n. 3, p. 259-276, 2011.

ŻYCHOWSKI, J. Impact of cemeteries on groundwater chemistry: a review. Catena, v. 93, n. 3, p. 29-37, 2012. 